\title{
High $Q_{S c S}$ beneath the Ontong Java Plateau
}

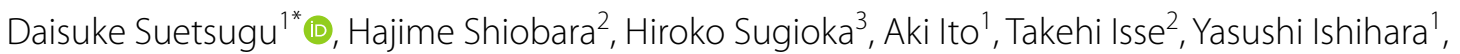 \\ Satoru Tanaka', Masayuki Obayashi', Takashi Tonegawa' ${ }^{1}$, Junko Yoshimitsu' ${ }^{1}$ and Takumi Kobayashi ${ }^{3}$
}

\begin{abstract}
The Ontong Java Plateau (OJP) in the southwest Pacific is the largest oceanic large igneous provinces (LIP) on Earth. Detailed seismic structure of the plateau has not been understood well because of sparse seismic stations. We investigated seismic attenuation of the mantle beneath the plateau by analyzing data from temporary seismic stations on the seafloor and islands in and around the plateau. We analyzed the spectra of multiple ScS waves to determine the average attenuation of the mantle $\left(Q_{S c S}\right)$ beneath the plateau. We estimated the average $Q_{S c S}$ values for the paths with bounce points located in the plateau to be 309 , which is significantly higher than the average (i.e., weaker attenuation than average) estimated in the western Pacific and is close to that of stable continents. We obtained positive residuals of $6 \mathrm{~s}$ for travel times of multiple ScS waves, which indicate that the average $S$ velocity in the entire mantle beneath the OJP is low. While the positive residuals are at least partially attributable to the Pacific Large Low Shear Velocity Province (Pacific LLSVP), it is difficult to conclude whether low-velocity anomalies are required in the OJP upper mantle to explain the residuals from the multiple ScS analysis.
\end{abstract}

Keywords: Seismic attenuation, Travel time, Multiple ScS phases, Ontong Java Plateau, Large igneous provinces, Broadband ocean-bottom seismograph

\section{Introduction}

The Ontong Java Plateau (OJP) is the most voluminous large igneous province (LIP) in the oceanic region of the Earth (Fig. 1), whose elevation is approximately $2000 \mathrm{~m}$ above the surrounding seafloor. The OJP is known to have been emplaced primarily at 120 and 90 Ma by massive volcanism (e.g., Coffin and Eldholm 1994; Neal et al. 1997) based on petrological and geochemical studies, but the cause of this volcanism remains controversial. Previous studies of seismic tomography using seismological data from islands in the region surrounding the OJP showed an anomalous mantle structure beneath the OJP, although the seismic images are not in agreement with each other. Richardson and Okal (2000) performed surface wave tomography using data from four temporary stations on islands in the northern margin of the OJP, which showed a low-velocity zone of $-5 \%$ down to $300 \mathrm{~km}$ beneath the entire OJP region. Based on an SKS

\footnotetext{
*Correspondence: dai@jamstec.go.jp

1 Japan Agency for Marine-Earth Science and Technology, 2-15,

Natsushima, Yokosuka, Kanagawa 237-0061, Japan

Full list of author information is available at the end of the article
}

splitting analysis, Klosko et al. (2001) interpreted the lowvelocity zone obtained by Richardson and Okal (2000) as a rheologically strong and chemically distinct mantle root of the OJP. On the other hand, Covellone et al. (2015) conducted surface wave tomography using earthquake and ambient noise data from permanent seismic stations in the western Pacific. Their model has a high-velocity anomaly in the center of the OJP down to $100 \mathrm{~km}$. The contradictory results obtained in the previous studies suggest that even first-order images, such as the presence of the low-velocity zone, remain to be resolved.

The discrepancy in the previous seismic images is mainly due to a shortage of in situ geophysical observations. To improve the spatial resolution for the geophysical structure beneath the OJP, we deployed a new temporary seismological and electromagnetic observation network, referred to herein as the OJP array, in the OJP and its vicinity (Suetsugu et al. 2018). In the present study, we analyzed seismic attenuation in the mantle beneath the OJP using data from the OJP array, which could provide another constraint on the mantle structure beneath the OJP. Only one study has been performed on the seismic attenuation beneath the OJP (Gomer 


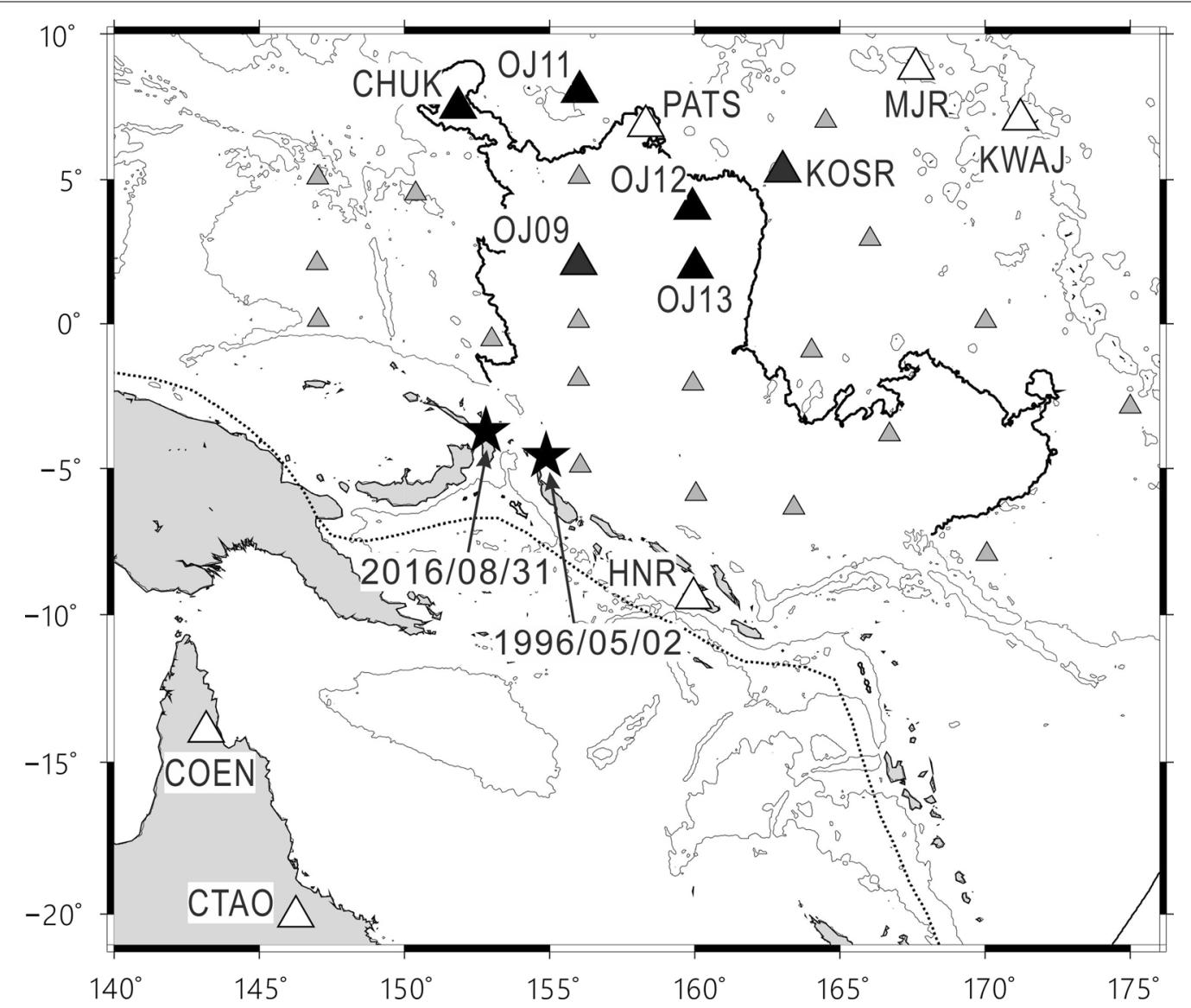

Fig. 1 Map showing seismological stations of the OJP array and permanent stations around the OJP. The black and small gray triangles denote the stations of the OJP array, and the open triangles denote permanent stations. Seismograms at the locations of the black and open triangles were analyzed in the present study. The small gray triangles denote stations with low signal-to-noise ratios of multiple ScS waves or stations that were terminated at the time of the event on Aug. 31, 2016

and Okal 2003) by analyzing multiple ScS waves $\left(Q_{\mathrm{ScS}}\right)$, which indicated that the attenuation in the OJP mantle was weak (high $Q_{\mathrm{ScS}}$ ). However, whether attenuation is weak over the entire OJP region remains unclear, because attenuation could be analyzed for a single event-station pair because only one pair was available for the analysis of multiple ScS waves due to few seismological stations located in the OJP.

While spatial resolution in global three-dimensional attenuation models have been improved recently (see review by Romanowicz and Mitchell 2015), they show variable results for the OJP region. Bhattacharyya et al. (1996) analyzed S and SS waves to determine the global distribution of Qs in the upper mantle. They showed that Qs beneath the OJP region is similar to the global average. Warren and Shearer (2002) analyzed spectra of P and PP waves to determine a global attenuation model, indicating that the OJP region has weaker attenuation. Attenuation studies using Rayleigh waves showed that the OJP region has an attenuation that is weaker than or close to the global average (Selby and Woodhouse 2002; Dalton et al. 2008). At present, global attenuation tomography may still have difficulty in resolving the seismic attenuation of the OJP.

In the present study, we present $Q_{\mathrm{ScS}}$ values estimated from multiple ScS waves recorded at 12 stations, including six stations of the OJP array for a deep earthquake. We examine whether the high $Q_{\mathrm{ScS}}$ obtained by Gomer and Okal (2003) for a single event-station pair represents the seismic attenuation of the entire OJP region.

\section{Data}

We analyzed waveform data recorded by a temporary broadband seismic network (OJP array) on the OJP and its vicinity along with six permanent stations operated by the IRIS/IDA, IRIS/USGS, Geoscience Australia, and Pacific21 seismic networks. The OJP array, which consisted of 23 broadband ocean-bottom seismic (BBOBS) stations and two land-based broadband stations on the Chuuk and Kosrae islands (Fig. 1), was operated from late 
2014 to early 2017. We analyzed waveform data of a deep earthquake that occurred in the New Ireland region of Papua New Guinea on Aug. 31, 2016, which was nearly at the end of the observation period. The hypocenter parameters determined by USGS are $3.685^{\circ} \mathrm{S}, 152.792^{\circ} \mathrm{E}$, $476 \mathrm{~km}$, and 6.8 for latitude, longitude, focal depth, and moment magnitude, respectively (referred to as the 2016 event, Fig. 1). We also analyzed the data used in Gomer and Okal (2003) for comparison with the event that occurred beneath the Solomon Islands on May 2, 1996 (referred to as the 1996 event). Figure 2 shows examples of multiple ScS waves for the 2016 event, which is visible up to $\mathrm{ScS}_{3}$ on the bandpass-filtered seismogram at periods between 0.01 and $0.05 \mathrm{~Hz}$. Note that the BBOBS data at OJ13 have a signal-to-noise ratio that is comparable to that at the continental station CTAO for this event.

\section{Method}

We analyzed a multiple $\mathrm{ScS}$ phase pair $\left(\mathrm{ScS}_{\mathrm{n}+1}\right.$ and $\mathrm{ScS}_{\mathrm{n}}$, $\mathrm{sScS}_{\mathrm{n}+1}$ and $\mathrm{sScS}_{\mathrm{n}}$ ) for each event-station pair to measure seismic attenuation and travel time, where $n$ is the number of reflections at the core-mantle boundary. Multiple ScS waves are sensitive to structures near the source, station, and bounce points at the Earth's surface and the core-mantle boundary (CMB) (e.g., Liu and Tromp 2008). Analyzing the phase pair, the effects of

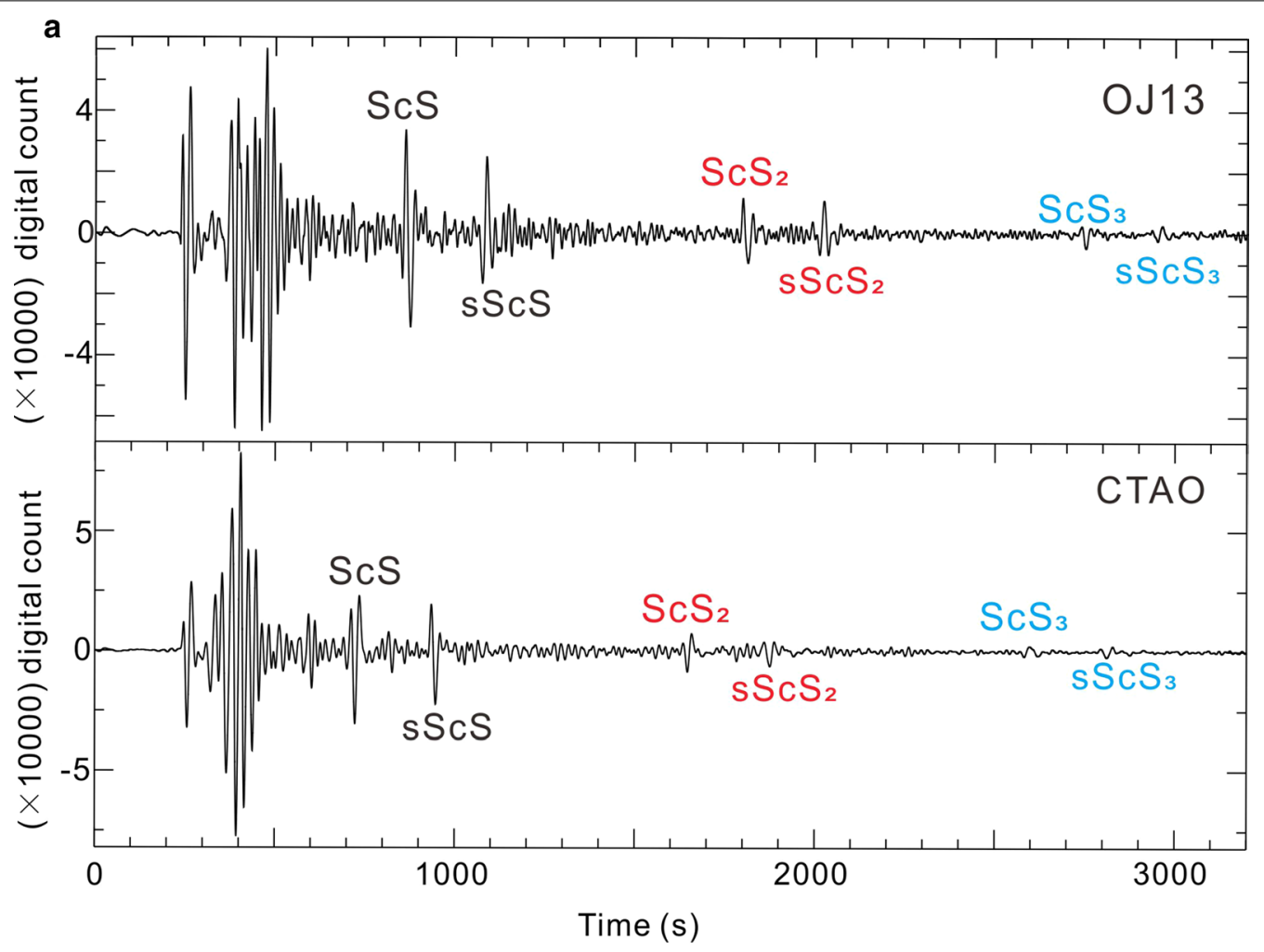

b
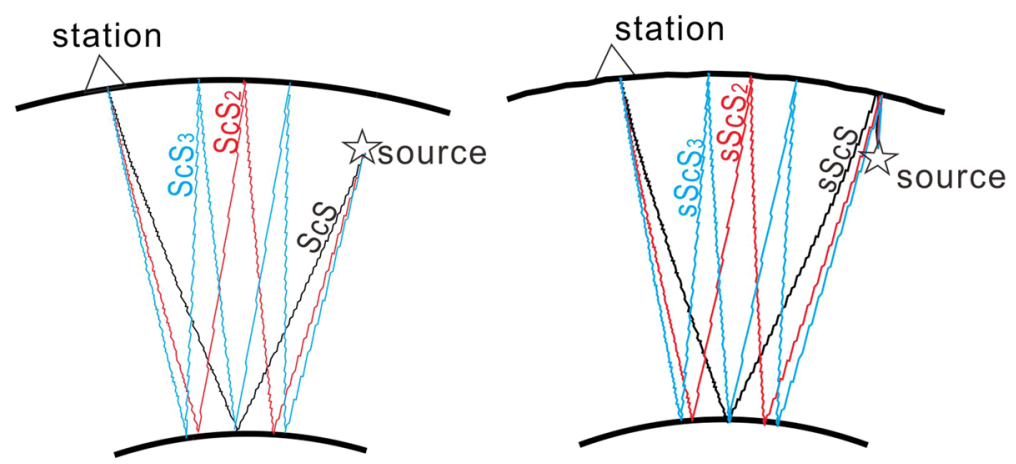

Fig. 2 a Transverse component seismograms for the 2016 event at OJ13 (top) and CTAO (bottom). b Schematic diagrams of multiple ScS ray paths 
structure near the source and station are substantially canceled, and the effects near the Earth's surface and the $\mathrm{CMB}$ are likely to remain. The effect of the Earth's surface is expected to be more enhanced than that near the CMB in measurements of seismic attenuation and travel time, because of much lower velocities near the Earth's surface compared to those near the CMB. Even so, the CMB effect should be also taken into consideration in the present study, because the lower mantle beneath the OJP is known as the Pacific Large Low Shear Velocity Province (Pacific LLSVP) of low shear velocity and strong attenuation (e.g., Garnero and McNamara 2008; Ritsema et al. 2010; Konishi et al. 2017).

We used a spectral ratio method to measure $Q_{\mathrm{ScS}}$ along the propagation path in the mantle from an event to each station (e.g., Jordan and Sipkin 1977; Nakanishi 1979; Suetsugu 2001). We applied the stacking procedure for multiple ScS spectra developed by Jordan and Sipkin (1977) to the spectral ratio method. In this method, $Q_{\mathrm{ScS}}$ is estimated from the ratio of stacked spectra of a multiple ScS pair $\left(\mathrm{ScS}_{\mathrm{n}+1} / \mathrm{ScS}_{\mathrm{n}}\right.$ and $\left.\mathrm{sScS}_{\mathrm{n}+1} / \mathrm{sScS}_{\mathrm{n}}\right)$ for each event-station pair.

We used a time window of $180 \mathrm{~s}$ of the rotated transverse component seismograms to compute the multiple ScS spectra. The starting time of the first phase was placed $40 \mathrm{~s}$ prior to the theoretical IASP91 arrival time (Kennett and Engdahl 1991). We chose this starting time to avoid errors in $Q_{\mathrm{ScS}}$ caused by crustal reverberations (Isse and Nakanishi 1997). A 30\% cosine taper was applied to two phases when the spectra were computed. We calculated noise power spectra from a 180-s-long record preceding the first phase and smoothed with a running average of $0.01 \mathrm{~Hz}$, from which we estimated the standard errors for the weighting factor of stacking (Jordan and Sipkin 1977). Geometrical spreading was corrected for the amplitude of multiple ScS waves. The logarithm of the stacked spectral ratio $A(f)$ is related to $Q_{\mathrm{ScS}}$ by

$$
\ln A(f)=-\frac{\pi T f}{Q_{\mathrm{ScS}}}+\varepsilon,
$$

where $T$ is the travel time difference between the two phases, which is determined by cross-correlating the two phases, $f$ is frequency, and $\varepsilon$ is an error term. We discarded the phase pairs for which the cross-correlation was less than 0.6. The $Q_{\mathrm{ScS}}$ value was computed from Eq. (1) by applying a least-squares line fitting technique to $\ln A(f)$. The frequency range is basically from 0.01 to $0.05 \mathrm{~Hz}$, whereas the highest and lowest limits of frequencies vary within $0.015 \mathrm{~Hz}$ based on the frequencydependent signal-to-noise ratio at each event-station pair. Travel time residuals of $\mathrm{ScS}_{\mathrm{n}+1}-\mathrm{ScS}_{\mathrm{n}}$ and $\mathrm{sScS}_{\mathrm{n}+1^{-}}$ $\mathrm{sScS}_{\mathrm{n}}$ were also obtained by cross-correlating waveforms of a phase pair. The residuals were corrected for Earth's ellipticity and water depths at surface bounce points. Figure 3 shows examples of $Q_{\mathrm{ScS}}$ measurements at OJ13 and HNR stations. The slope of amplitude spectra with respect to the frequency is gentler at $\mathrm{OJ} 13$ than at HNR, indicating that $Q_{\mathrm{ScS}}$ is higher (weaker attenuation) at OJ13 than that at HNR.

\section{Results}

We obtained $Q_{\mathrm{ScS}}$ from eight land-based stations and four BBOBS stations in the northern part of the OJP array, as shown in Table 1. The operation of the BBOBS stations in the eastern part of the array had already been terminated at the time of the 2016 event. The BBOBS stations in the western and central parts of the array did not record multiple $\mathrm{ScS}$ waves with a good $\mathrm{S} / \mathrm{N}$ ratio. As a result, we could determine $Q_{\mathrm{ScS}}$ with bounce points of multiple ScS waves located only in the northern half of the OJP.

Figure 4a, b illustrates the $Q_{\mathrm{ScS}}$ values and the travel time residuals plotted at surface bounce points, respectively. The $Q_{\mathrm{ScS}}$ values with the bounce points located in the OJP range from 213 to 413, whereas the standard errors are large (19-227) (Table 1), as estimated from the signal-to-noise ratio of the multiple ScS spectra at each station (Jordan and Sipkin 1977). The large standard errors are due to a large horizontal-component noise on the ocean-bottom seismograph (e.g., Suetsugu and Shiobara 2014). The average $Q_{\mathrm{ScS}}$ value beneath the OJP calculated from $Q_{\mathrm{ScS}}$ at each station is $309 \pm 55$, which is significantly higher than the average $Q_{\mathrm{ScS}}$ computed from global one-dimensional models, such as the PREM (223, Dziewonski and Anderson 1981) or the QL6 model (233, Durek and Ekström 1996), or that for the western Pacific (156 \pm 17$)$ estimated by Sipkin and Jordan (1980), despite the significant variations of the observed $Q_{\mathrm{ScS}}$ values. Travel time residuals with the bounce points located in the OJP range from $4.5 \mathrm{~s}$ to $6.9 \mathrm{~s}(6.0 \mathrm{~s} \pm 0.8 \mathrm{~s})$ with respect to those calculated from the IASP91 model, which is markedly larger than those with the bounce points outside the OJP (1.4-4.2 s). The large positive residuals beneath the OJP indicate that the average $S$ velocity of the entire mantle is low beneath the OJP.

\section{Discussion and conclusion}

We estimated the $Q_{\mathrm{ScS}}$ values to be $324 \pm 34$ and $218 \pm 20$ at PATS and CTAO, respectively, for the 1996 event, which is the event used by Gomer and Okal (2003). These values are close to the value of 366 (error bar from 253 to 634) at PATS and 177-200 at CTAO, as obtained by Gomer and Okal (2003). The relatively small difference between the two studies is due mainly to difference in of the methodologies of the two studies, such as a time-windowing method. 


\section{a Waveforms (OJ13)}
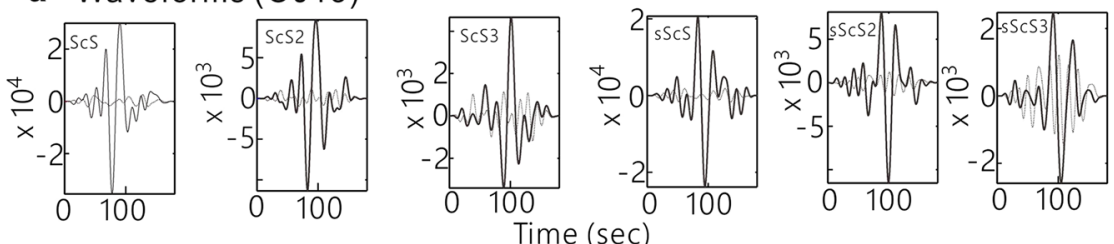

b Amplitude spectra (OJ13)
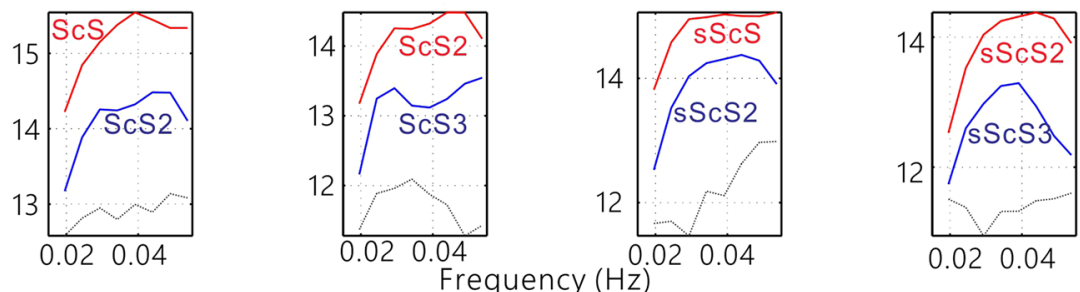

c Stacked spectral ratio (OJ13)
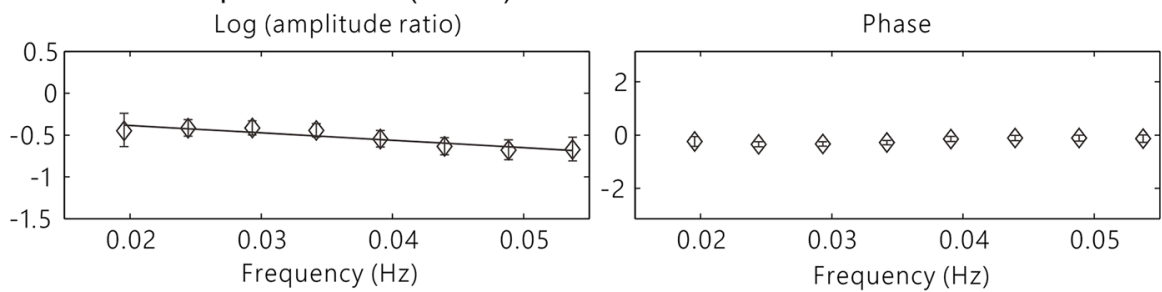

d Waveforms (HNR)
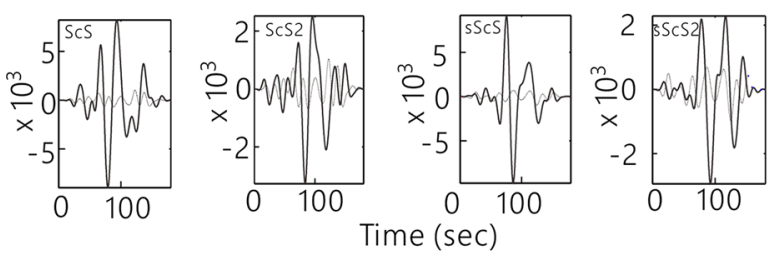

e Amplitude spectra $(H N R)$



\section{f Stacked spectral ratio (HNR)}
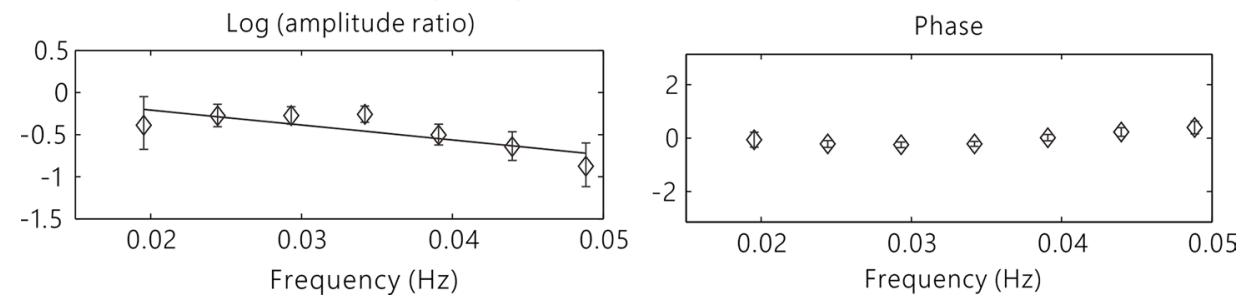

Fig. 3 Multiple ScS waveforms $(\mathbf{a}, \mathbf{d})$, amplitude spectra $(\mathbf{b}, \mathbf{e})$, and stacked spectral ratios $(\mathbf{c}, \mathbf{f})$ at OJ13 (a-c) and HNR (d-f) stations. In (a, d), the dotted curves denote the noise waveforms before arrivals of the multiple ScS waves. In $(\mathbf{b}, \mathbf{e})$, spectra of $\mathrm{ScS}_{n}$ and $\mathrm{sScS} \mathrm{S}_{n}$ are indicated by red curves and those of $\mathrm{ScS}_{\mathrm{n+1}}$ and $\mathrm{SScS}_{\mathrm{n+1}}$ by blue curves, those of noises are by dotted curves. In (c, $\mathbf{f}$ ), the logarithm of the amplitude (left) and the phase (right) of the stacked spectral ratio are shown, respectively. Errors are estimated from noise spectra. A line fitting technique gives $331 \pm 58$ at OJ13 and $165 \pm 54$ at $\mathrm{HNR}$ 
Table $1 Q_{\mathrm{ScS}}$, standard errors, travel time residuals, and theoretical travel time residuals calculated from S40RTS (Ritsema et al. 2010), and pairs of multiple ScS used in the present study

\begin{tabular}{|c|c|c|c|c|c|c|c|}
\hline Station & $\mathrm{ScS}_{2} / \mathrm{ScS}_{1}$ & $\mathrm{ScS}_{3} / \mathrm{ScS}_{2}$ & $\mathrm{sScS} / \mathrm{sScS}_{2}$ & $\mathrm{sScS}_{2} / \mathrm{sScS}$ & $Q_{\mathrm{scS}}$ & $\delta \mathrm{T}_{\mathrm{scs}}$ & $\delta \mathrm{T}_{\mathrm{ScS}}(\mathrm{S} 40 \mathrm{RTS})$ \\
\hline \multicolumn{8}{|c|}{ Event on $2016 / 8 / 31$} \\
\hline PATS & O & & O & & $239 \pm 59$ & 6.5 & 2.8 \\
\hline CHUK & O & & O & O & $213 \pm 20$ & 5.6 & 1.4 \\
\hline KOSR & O & O & O & & $413 \pm 227$ & 5.4 & 3.9 \\
\hline OJ09 & & & O & & $290 \pm 158$ & 4.5 & 2.8 \\
\hline OJ11 & O & & O & & $334 \pm 52$ & 6.0 & 2.3 \\
\hline OJ12 & O & O & & & $333 \pm 97$ & 6.0 & 3.3 \\
\hline OJ13 & O & O & & & $331 \pm 59$ & 5.2 & 3.5 \\
\hline MJR & O & O & O & & $309 \pm 117$ & 6.7 & 5.3 \\
\hline KWAJ & O & O & & O & $307 \pm 59$ & 6.9 & 4.2 \\
\hline HNR & O & & O & & $165 \pm 54$ & 3.7 & 2.2 \\
\hline CTAO & O & O & & & $204 \pm 60$ & 2.7 & 2.5 \\
\hline COEN & O & O & O & & $109 \pm 26$ & 4.2 & 0.4 \\
\hline \multicolumn{8}{|c|}{ Event on 1996/5/2 } \\
\hline PATS & O & O & & & $324 \pm 34$ & 6.3 & 3.2 \\
\hline CTAO & O & O & & & $218 \pm 20$ & 1.4 & 3.0 \\
\hline
\end{tabular}

$\delta \mathrm{T}_{\mathrm{SCS}}$ is a travel time residual for a phase pair
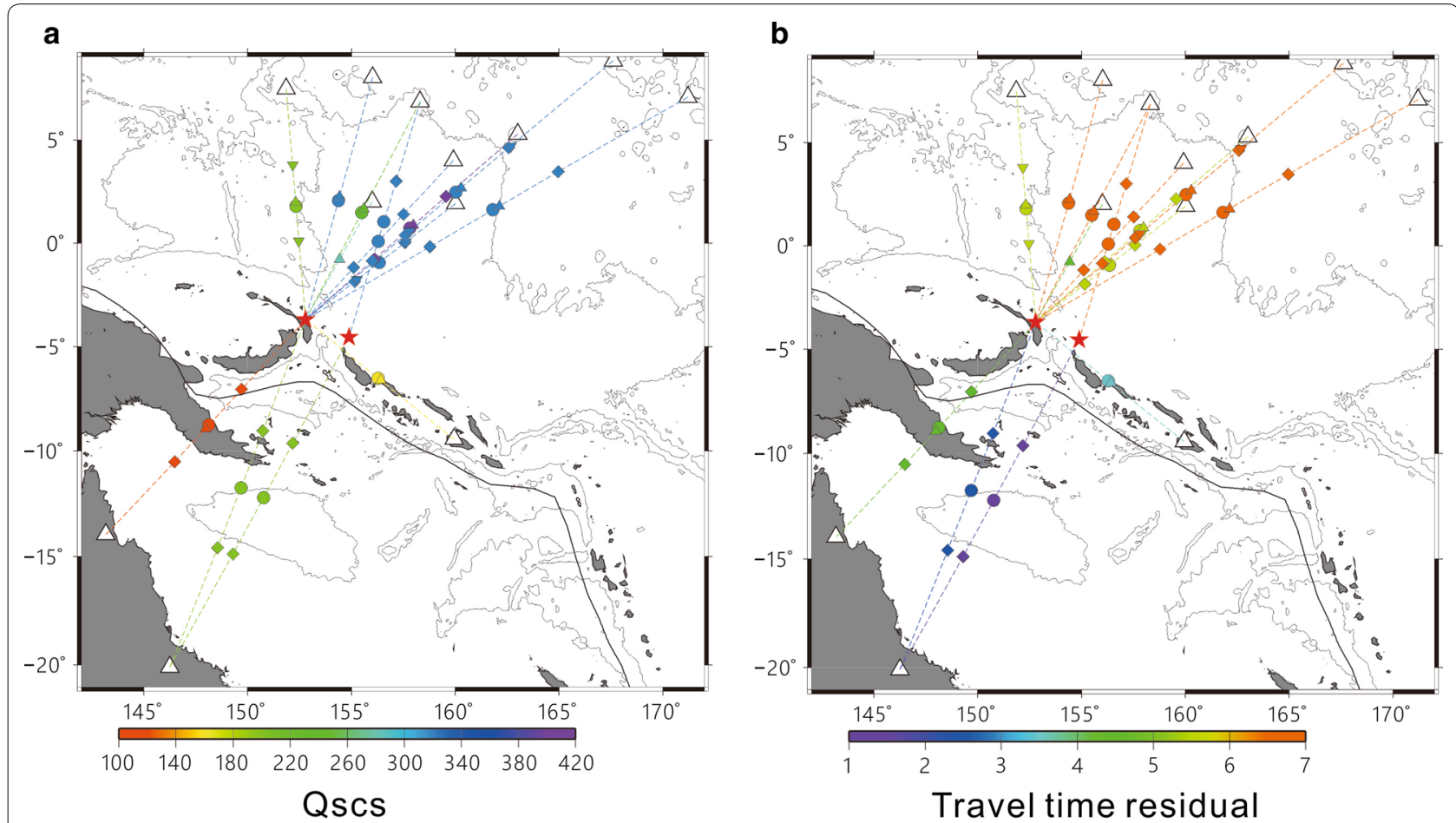

Fig. $4 Q_{S c S}$ values (a) and travel time residuals (b) of multiple ScS waves estimated in the present study. Surface bounce points of ScS2, ScS3, sScS, sScS2, and sScS3 waves are denoted by circles, diamonds, crosses, solid triangles, and inverted triangles, respectively. The dotted lines are great circles from event to stations (projection of ScS wave paths on the surface). The colors of the symbols and the dotted curves represent $Q_{S c S}$ values in (a) and travel time residuals in (b). Stars and open triangles are epicenters and stations, respectively 
Since there was no previous $Q_{\mathrm{ScS}}$ study beneath the OJP in the past, except for Gomer and Okal (2003), we compared $Q_{\mathrm{ScS}}$ values obtained in previous studies with those of the present study in broader regions, including the OJP. Sipkin and Jordan (1980) and Chan and Der (1988) estimated the $Q_{\mathrm{ScS}}$ values from Fiji-Tonga events to central Japan as $173 \pm 37$ and $214 \pm 42$, respectively, which are higher than the average $Q_{\mathrm{ScS}}$ value of 156 in the western Pacific (Sipkin and Jordan 1980). The $Q_{\mathrm{ScS}}$ values obtained by the present study $(309 \pm 55)$ are even higher than those obtained by previous studies, probably because multiple $\mathrm{ScS}$ waves analyzed by the two previous studies sampled a broader region from the Fiji-Tonga region to Japan, including the OJP, than the present study. The $Q_{\mathrm{ScS}}$ beneath the OJP is close to those beneath the stable continents of 280-333 (Chan and Der 1988; Revenaugh and Jordan 1991; Sipkin and Revenaugh 1994). The $Q_{\mathrm{ScS}}$ values beneath the Solomon subduction zone and the Coral Sea are 100-200, which is significantly lower than those of the OJP. Very low $Q_{\mathrm{ScS}}(109)$ are observed at the COEN station in the present study, probably because the multiple ScS phases travel long distances in the tectonically active region of the Papua New Guinea.

While it is difficult to estimate Qs of the upper and lower mantle separately from multiple ScS waves of nearly vertical paths, the spectral ratio and travel time difference of sScS and ScS waves bear information on the $Q$ s and $S$ velocity anomaly in the upper mantle above the 2016 event (Additional file 1: Table S1, Figure S1). The average $Q \mathrm{~s}$ in the upper $500 \mathrm{~km}$ above the source is estimated to be $98 \pm 15$, which is close to the Qs of 104 for the PREM. The travel time residual of $\mathrm{sScS}-\mathrm{ScS}$ is $5.5 \pm 0.6 \mathrm{~s}$ at stations located toward the OJP from the source, which corresponds to $S$ velocity lower by $2.4 \%$ than that of the IASP91 model in the upper $500 \mathrm{~km}$ of the 2016 event. However, these values may not represent the upper mantle beneath the OJP, because the Qs and travel time residual from the $\mathrm{sScS}$ and $\mathrm{ScS}$ pairs are affected by the Papua New Guinea and Solomon Islands subduction zones with presumably strong lateral heterogeneities. Next, we referred to the existing $Q$ s model of the lower mantle to estimate the Qs of the OJP upper mantle from the $Q_{\mathrm{ScS}}$ value of 309 using a ray theory. Using the PREM $Q$ s value of 312 for the lower mantle, the $Q$ s of the upper mantle is estimated to be 303 . Since the LLSVP is seated in the OJP lower mantle, the effect of the LLSVP on attenuation should be taken into consideration. Konishi et al. (2017) determined one-dimensional $V$ s and Qs models at depths greater than $2000 \mathrm{~km}$ using a waveform inversion technique beneath the western Pacific region, including the OJP. The Qs values beneath the OJP are approximately 260 at depths from $2000 \mathrm{~km}$ to $2850 \mathrm{~km}$ and 216 at depths from 2850 to the core-mantle boundary.
Konishi et al. (2017) attributed the low Qs values to thermo-chemical anomalies of the Pacific LLSVP. Using the Qs of 260 at depths from $2000 \mathrm{~km}$ to the core-mantle boundary and the Qs of PREM in the rest of the lower mantle, we obtained a Qs value of 367 for the OJP upper mantle. The Qs in the OJP upper mantle is higher than those computed from one-dimensional models, such as the PREM (134) and the laterally averaged SEMUCBWM1 model (130, Karaoğlu and Romanowicz 2018). Considering the similarity of the $Q_{\mathrm{ScS}}$ values beneath the OJP by the present study and those of stable continents reported in previous studies, as mentioned above, we estimated the upper mantle $Q$ s values by a ray theory beneath the continents from the $Q_{\mathrm{ScS}}$ values obtained in the previous studies (Chan and Der 1988; Revenaugh and Jordan 1991; Sipkin and Revenaugh 1994) by assuming a lower mantle Qs to be that of PREM and compared these values with the $Q$ s estimated for the OJP upper mantle. The $Q_{\mathrm{ScS}}$ of 280-333 for the stable continents resulted in an upper mantle Qs of 244-395, which is close to the Qs of the OJP upper mantle estimated above (303 and 367). The upper mantle $Q$ s of the OJP is in the estimated range of those for stable continents.

The travel time residuals of multiple ScS waves are $6.0 \pm 0.8 \mathrm{~s}$, which indicates that the average velocity of the entire mantle beneath the OJP is low. The LLSVP is located in the lower mantle at depths from $1000 \mathrm{~km}$ to the core-mantle boundary, and the observed positive residuals should be attributable, at least partially, to the low velocities of the LLSVP. We examined how large residuals can be explained by the LLSVP by calculating the theoretical residuals with the three-dimensional S velocity model S40RTS (Ritsema et al. 2010) using a ray theory. Although a geographical pattern of the observed residuals is reproduced in the theoretical residuals (largely positive residuals beneath the OJP and less positive residuals outside the OJP), the theoretical residuals are $3.3 \pm 1.1 \mathrm{~s}$, which is approximately half of the observed residuals. While the upper mantle of the S40RTS model has strong high-velocity (1.5-3\% in the shallowest $100 \mathrm{~km}$ ) and low-velocity anomalies ( -1 to $-3 \%$ at depths from $200 \mathrm{~km}$ to $300 \mathrm{~km}$ ), the net effects on multiple ScS waves are negligible, because the effects are canceled for nearly vertical paths of the multiple ScS waves. The theoretical residuals are therefore mainly due to the broadly low-velocity anomalies of the LLSVP. Assuming that the remaining $2.7 \mathrm{~s}$ occurs in the entire upper mantle and the top $300 \mathrm{~km}$ depths, the velocity anomalies are $-0.9 \pm 0.4 \%$ and $-1.9 \pm 0.8 \%$, respectively. There are two ways to interpret the remaining positive residuals. One is the positive residuals caused by the low-velocity zone in the upper mantle obtained by Richardson and Okal (2000), 
and the other is the positive residuals due to underestimated correction of the LLSVP. Amplitudes of velocity anomalies estimated by seismic tomography are well known to depend on the parameterization and regularization used in tomography. Some models have velocities as low as approximately -2.5 to $-3 \%$ in the LLSVP (e.g., Lu and Grand 2016), whereas the S40RTS has velocities as low as approximately -1.5 to $-2 \%$. Determining the velocity structure in the upper mantle using multiple ScS studies is difficult. Seismic tomography using data from the OJP array is expected to provide a tight constraint on the velocity structure beneath the OJP.

In summary, the $Q_{\mathrm{ScS}}$ in the mantle beneath the northern OJP is estimated to be $309 \pm 55$, which is consistent with the result of Gomer and Okal (2003). This is higher than the average $Q_{\mathrm{ScS}}$ in the western Pacific and that calculated from global one-dimensional $Q$ s models and is close to the $Q_{S c S}$ beneath stable continents. Assuming the lower mantle Qs based on existing Qs models with LLSVP effects accounted for, the seismic attenuation in the upper mantle is probably weak beneath the OJP, as is that of stable continents. The travel times of multiple $\mathrm{ScS}$ waves are as large as $6 \mathrm{~s}$. While the positive residuals are at least partially explained by the effect of the Pacific LLSVP in the lower mantle, it is difficult to conclude whether the low-velocity zone in the upper mantle is required to explain the positive residuals, which remains to be concluded by seismic tomography using data from in situ stations such as the OJP array.

\section{Supplementary information}

Supplementary information accompanies this paper at https://doi. org/10.1186/s40623-019-1077-8.

Additional file 1: Table A1. Qs and travel time residuals estimated from SSCS-SCS pairs for the 2016 event. PATS, CHUK, KOSR, OJ09, OJ11, OJ12, OJ13 and MJR are located towards the OJP from the epicenter. Figure A1. Qs obtained from spectral ratio of sScS and SCS phases for the 2016 event (star). Surface bounce points of sScS phase are denoted by crosses. The dotted lines are surface projections of sScS ray paths in the upper $500 \mathrm{~km}$ of the mantle. The colors of the symbols and the dotted curves represent Qs values.

\section{Abbreviations}

OJP: Ontong Java Plateau; BBOBS: broadband ocean-bottom seismograph; PREM: Preliminary Reference Earth Model; IRIS: Incorporated Research Institutions for Seismology; IDA: International Deployment of Accelerometers; USGS: US Geological Survey.

\section{Acknowledgements}

The authors are grateful to the captains and crews of RN MIRAI of JAMSTEC and R/V HAKUHO-MARU of JAMSTEC for the installation and recovery cruises, respectively. Their devoted efforts led to the success of the OJP array observation. The authors thank IRIS Data Management Center for making their data available. We thank B. Romanowicz and an anonymous reviewer for their constructive comments, which substantially improved the present study.
The present study was supported by a Grant-in-Aid for Scientific Research (15H03720) from the Japan Society for the Promotion of Science.

\section{Authors' contributions}

DA organized the seafloor observation, analyzed data, and wrote the manuscript. HSH, HSU, Al, TI, and TK performed the seafloor observation. YI, ST, MO $\mathrm{TT}$, and JY organized and performed the island observation. All authors read and approved the final manuscript.

\section{Funding}

The present study was supported by a Grant-in-Aid for Scientific Research (15H03720) from the Japan Society for the Promotion of Science and Grants for Operating Expenses of JAMSTEC and the University of Tokyo.

\section{Availability of data and materials}

Data supporting the results of the present article are available upon request to the authors

\section{Ethics approval and consent to participate}

Not applicable.

\section{Consent for publication \\ Not applicable.}

\section{Competing interests}

The authors declare that they have no competing interests.

\section{Author details}

1 Japan Agency for Marine-Earth Science and Technology, 2-15, Natsushima, Yokosuka, Kanagawa 237-0061, Japan. ${ }^{2}$ Earthquake Research Institute, The University of Tokyo, 1-1-1, Yayoi, Bunkyo, Tokyo 113-0032, Japan. ${ }^{3}$ Department of Planetology, Graduate School of Science, Kobe University, 1-1 Rokkodai-cho, Nada-ku, Kobe, Hyogo 657-8501, Japan.

Received: 3 January 2019 Accepted: 26 August 2019

Published online: 06 September 2019

\section{References}

Bhattacharyya J, Masters G, Shearer PM (1996) Global lateral variations of shear wave attenuation in the upper mantle. J Geophys Res 101:22273-22289

Chan WW, Der ZA (1988) Attenuation of multiple SCS in various parts of the world. Geophys J Int 92:303-314

Coffin MF, Eldholm O (1994) Large igneous provinces: crustal structure, dimensions, and external consequences. Rev Geophys 32:1-36

Covellone BM, Savage B, Shen Y (2015) Seismic wave speed structure of the Ontong Java Plateau. Earth Planets Sci Lett 420:140-150

Dalton CA, Ekström G, Dziewonski AM (2008) The global attenuation structure of the upper mantle. J Geophys Res. https://doi.org/10.1029/2007JB0054 29

Durek JJ, Ekström G (1996) A radial model of anelasticity consistent with longperiod surface-wave attenuation. Bull Seismol Soc Am 86:144-158

Dziewonski A, Anderson DL (1981) Preliminary reference Earth model. Phys Earth Planet Inter 25:297-356

Garnero EJ, McNamara AK (2008) Structure and dynamics of Earth's lower mantle. Science 320:626-628. https://doi.org/10.1126/science.1148028

Gomer B, Okal EA (2003) Multiple-SCS probing of the Ontong-Java Plateau. Phys Earth Planet Inter 138:317-331

Isse T, Nakanishi I (1997) The effect of the crust on the estimation of mantle $\mathrm{Q}$ from spectral ratios of multiple ScS phases. Bull Seismol Soc Am 87:778-781

Jordan TH, Sipkin SA (1977) Estimation of the attenuation operator for multiple ScS waves. Geophys Res Lett 4:167-170

Karaoğlu H, Romanowicz B (2018) Inferring global upper-mantle shear attenuation structure by waveform tomography using the spectral element method. Geophys J Int 213:1536-1558. https://doi.org/10.1093/gji/ggy03 0

Kennett BLN, Engdahl ER (1991) Traveltimes for global earthquake location and phase identification. Geophys J Int 105:429-465. https://doi. org/10.1111/j.1365-246X.1991.tb06724.x 
Klosko ER, Russo RM, Okal EA, Richardson WP (2001) Evidence for a rheologically strong chemical mantle root beneath the Ontong-Java Plateau. Earth Planets Sci Lett 186:347-361

Konishi K, Fuji N, Deschamps F (2017) Elastic and anelastic structure of the lowermost mantle beneath the western Pacific from waveform inversion. Geophys J Int 208:1290-1304. https://doi.org/10.1093/gji/ggw450

Liu Q, Tromp J (2008) Finite-frequency sensitivity kernels for global seismic wave propagation based upon adjoint methods. Geophys J Int 174:265286. https://doi.org/10.1111/j.1365-246X.2008.03798.x

Lu C, Grand SP (2016) The effect of subducting slabs in global shear wave tomography. Geophys J Int 205:1074-1085. https://doi.org/10.1093/gji/ ggw072

Nakanishi I (1979) Attenuation of multiple ScS waves in the Japanese arc. Phys Earth Planet Inter 19:337-347

Neal C, Mahoney JJ, Kroenke LW, Duncan RA, Petterson MG (1997) The Ontong Java Plateau. In: Mahoney JJ, Coffin MF (eds) Large igneous provinces: continental, oceanic, and planetary flood volcanism, 100th edn. American Geophysical Union, Washington, pp 183-216. https://doi. org/10.1029/gm100p0183

Revenaugh J, Jordan TH (1991) Mantle layering from ScS reverberations 1. Waveform inversion of zeroth-order reverberations. J Geophys Res 96:19749-19762

Richardson W, Okal EA, van der Lee S (2000) Rayleigh-wave tomography of the Ontong-Java Plateau. Phys Earth Planet Inter 118:29-51

Ritsema J, Deuss A, van Heijst HJ, Woodhouse JH (2010) S40RTS: a degree-40 shear-velocity model for the mantle from new Rayleigh wave dispersion, teleseismic traveltime and normal-mode splitting function measurements. Geophys J Int 184:1223-1236. https://doi.org/10.1111/j.1365246X.2010.04884.X
Romanowicz, BA, Mitchell, BJ (2015) Deep earth structure: Q of the Earth from crust to core. In: Schubert G (ed). Treatise on geophysics. 2nd edn. pp 789-827

Selby ND, Woodhouse JH (2002) The Q structure of the upper mantle: constraints from Rayleigh wave amplitudes. J Geophys Res. https://doi. org/10.1029/2001JB000257

Sipkin SA, Jordan TH (1980) Regional variation of $Q_{S c S}$. Bull Seismol Soc Am 70:1071-1102

Sipkin SA, Revenaugh J (1994) Regional variation of attenuation and travel time in China from analysis of multiple-ScS phases. J Geophys Res 99:2687-2699

Suetsugu D (2001) A low $Q_{S c S}$ anomaly near the South Pacific Superswell. Geophys Res Lett 28:391-394

Suetsugu D, Shiobara H (2014) Broadband ocean bottom seismology. Ann Rev. Earth Planet Sci 42:27-43

Suetsugu D, Shiobara H, Sugioka H, Tada N, Ito A, Isse T, Baba K, Ichihara H, Ota T, Ishihara Y, Tanaka S, Obayashi M, Tonegawa T, Yoshimitsu J, Kobayashi T, Utada H (2018) The OJP array: seismological and electromagnetic observation on seafloor and islands in the Ontong Java Plateau. JAMSTEC Rep Res Dev 26:54-64. https://doi.org/10.5918/jamstecr.26.54

Warren LM, Shearer PM (2002) Mapping lateral variations in upper mantle attenuation by stacking P and PP spectra. J Geophys Res. https://doi. org/10.1029/2001JB001195

\section{Publisher's Note}

Springer Nature remains neutral with regard to jurisdictional claims in published maps and institutional affiliations.

\section{Submit your manuscript to a SpringerOpen ${ }^{\circ}$ journal and benefit from:}

- Convenient online submission

- Rigorous peer review

- Open access: articles freely available online

- High visibility within the field

- Retaining the copyright to your article

Submit your next manuscript at $\boldsymbol{\nabla}$ springeropen.com 